\title{
فلسفة الحكم في العصر الأموي
}

أ.د. عطا سلمان جاسم

\section{تقديم}

بالدهاء والمكر والحنكة استطاع معاوية بن أبي سفيان تحقيق ما يربوا اليه وهو لوصول الى السلطة بعد

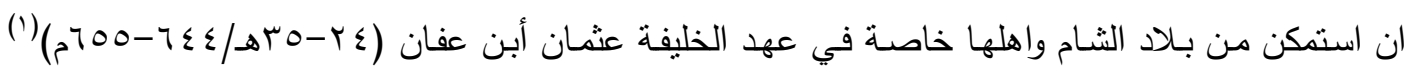
الذي عمل على تولية أقاربه من بني أمية أعمال الدولة المهمة، ولعل اتخاذه مروان بن الحكم كاتباً له، الذي أصبح مستودع أسرار الخليفة ومسنتاره ان سيطرة هؤلاء على مقاليد الأمور ، وبالنتيجة ان أدى ذلك الى فتتة استمرت لعدة سنوات، طالت أرواح الاف المسلمين، لم يستفد منها في النتيجة النهائية الا معاويـة المخطط الرئيسي للأحداث الذي أوصلته الى السلطة والحكم باسم الإسلام.

\section{نظام الحكم في العصر الأموي:}

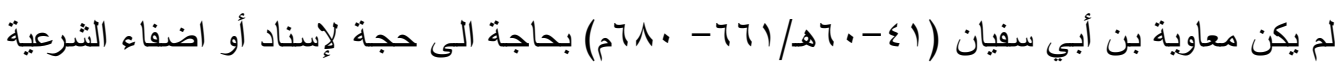
على طابع حكمه، فهو في نظر أصحابه واتباعه المطالب الثرعي بدم قريبه عثمان بن عفان (بِّئَ)، وهو

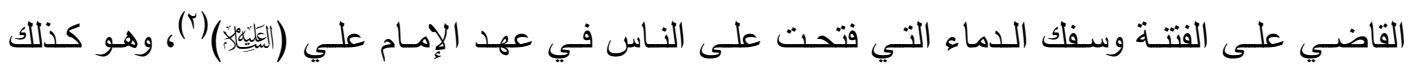
الصحابي الجليل المتجاوز بفضله فضل كبار الصحابة، كما روجت له الأقلام الأموية، لأغراض سياسية هدفها تبيان فضله ومكانته في الإسلام، وهي في الحقيقة روايات موضوعة لم يقرها الواقع ولا اساس لها من

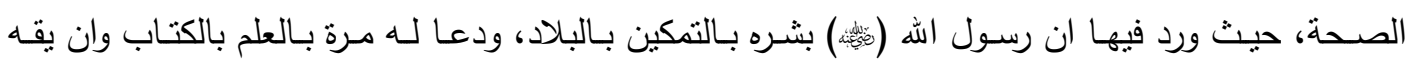
العذاب، ويملأ صدره علماً وحكماً، وهو رجل من أهل الجنة، يزاحم النبي (ثِئهَ) على بابها، وهو القوي الأمين

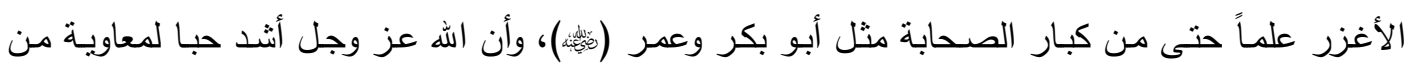

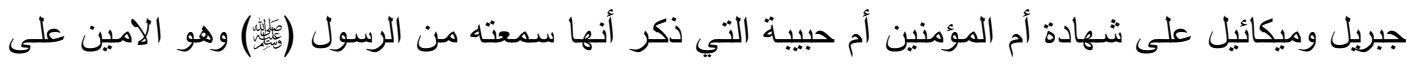

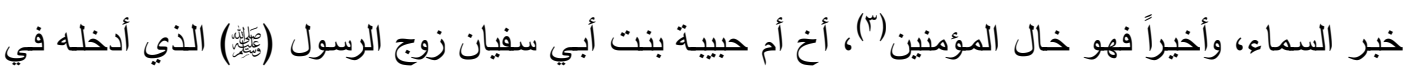


أمره، وجعله كاتباً له على الرغم من إسلامه المتأخر ، وكذلك رضى عنه الخلفاء الراشدين الثلاثة، فضلاً عن التهاء

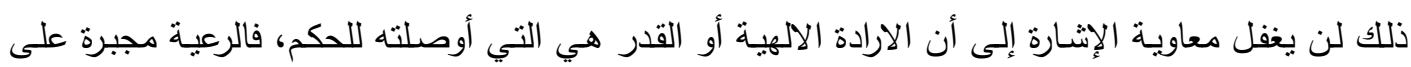

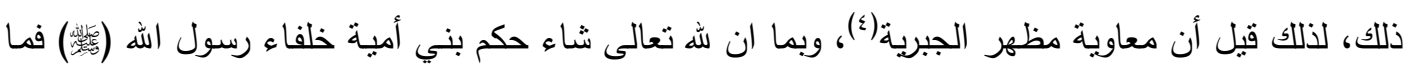

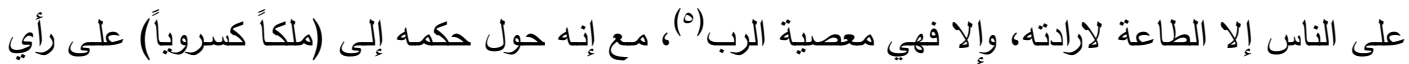

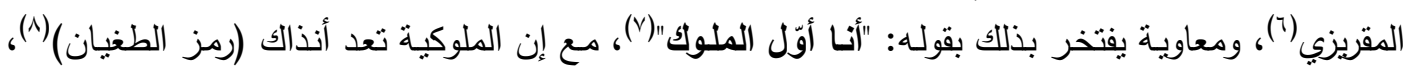

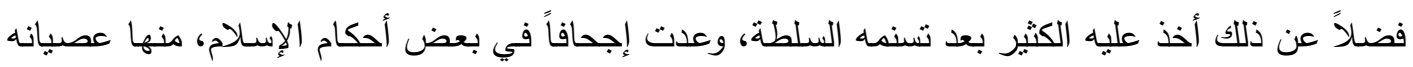

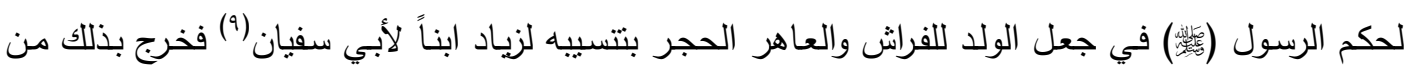

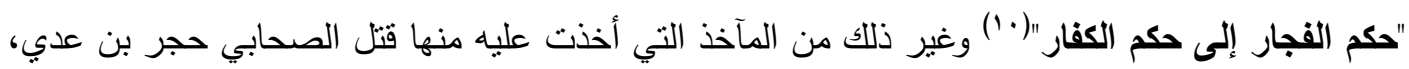

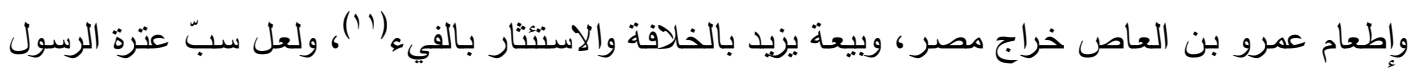

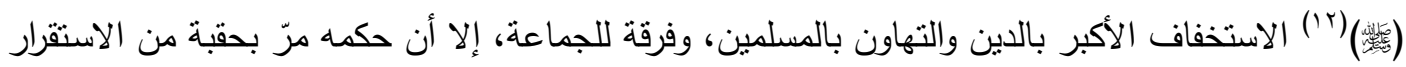

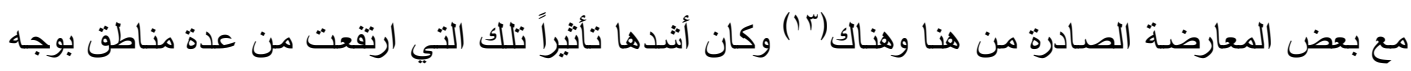

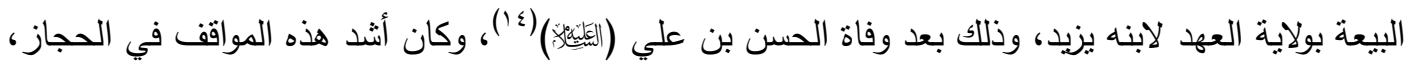

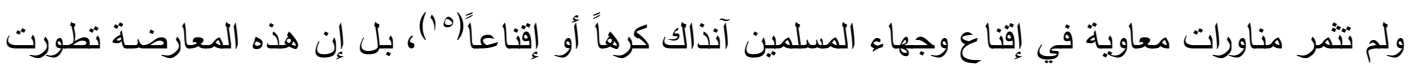

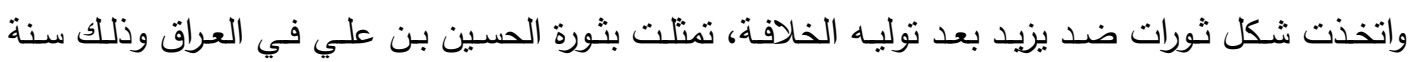

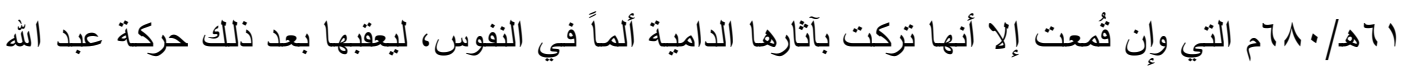

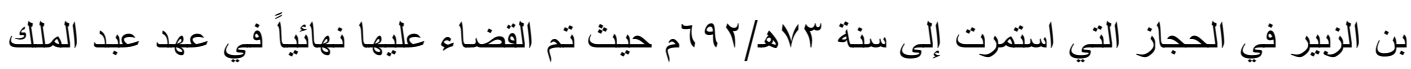

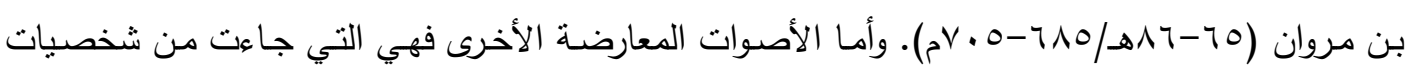

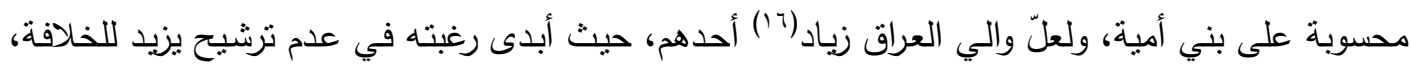

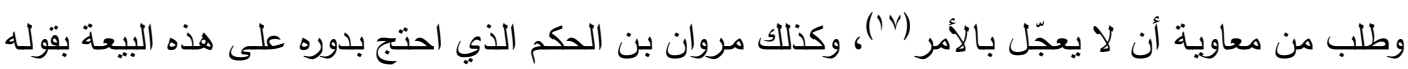

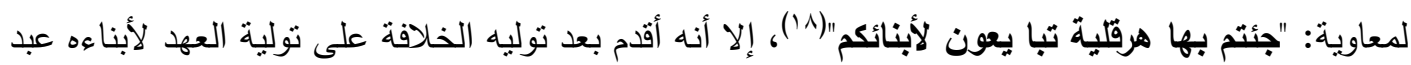
الملك من بعده عبد العزيز (19).

إن الاصرار لأخذ البيعة ليزيد قبل وفاة والده، وإن كانت شكلية، فإنها تعني إن معاوية ألزم نفسه وكذلك إنكا

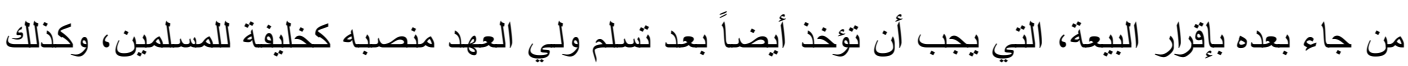

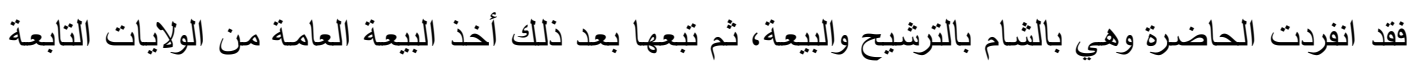


للاولة، ولكن أستني هنا شرط الفضل والسبق في الإسـلام، فيزيد تتقصه هذه الفضبلة، ومعاوية دارك لذلك،

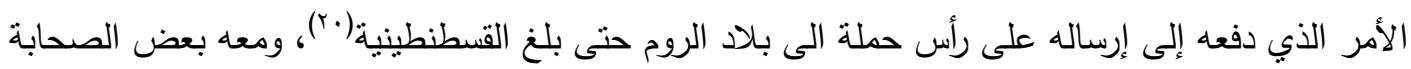
مثل أبو أيوب الأنصاري، وقد أراد معاوية عن ذلك اضفاء صفة الثجاعة والجهاد في الإسلام على يزيد، خطب معاويـة في المدينة لما قدم إليها وهو على المنبر ، وفيها ذكر الناس بفضل ابنه وشجاعته وإن أهل الثام بايعوا له بالعهد (r').

وممـا يـلاحظ عليه في الإدارة الأمويـة، هو انـه رغم اعتمـاد الخلافة على العنصـر العربي في الحكم والقيادة، فإنهم لم يستثتوا الموالي وأهل الذمة من تولي وظائف مهمة في الدولة، بل إن نجمهم أخذ بالصعود،

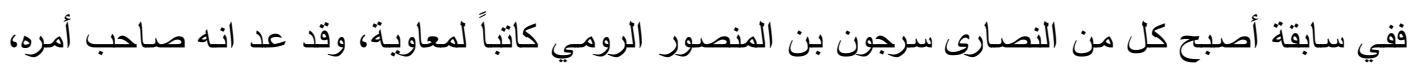
وكذلك ابن اثال على خراج مصر (rº). واتخذ معاوية أيضاً على حرسـه رجل من الموالي يقال لـه المختار وقيل ماللك، ويكنى أبا المخارق مولى لحمير ، وكان حاجبه سعد مولاه(rr)، وكان على خراج العراق مولاه عبد رجن

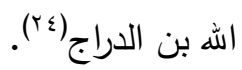

إن انتقال الخلافة من معاوبة إلى يزيد ابنه مغزاه أن أصبح الحكم وراثي محصور في بني أمبية، لم

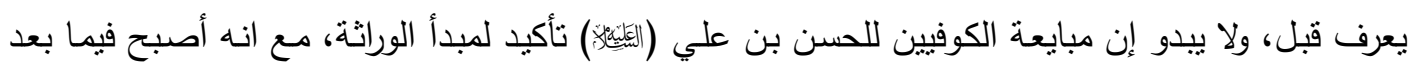

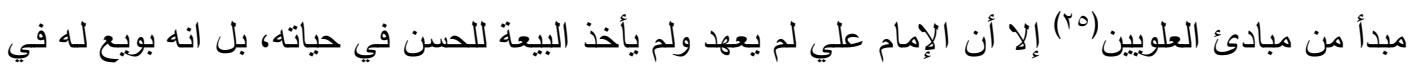
الكوفة من قبل أهلها(جr)، ولم يجبرهم أحد على ذلك، ولكن لما وجدوا فيه من شروط وصفات تتوفر فيه، فهو من أفاضل المسلمين ومن أهل البيت، فهو أهلا لها لا لأنه ابن الخليفة السابق، كما كان حال يزيد الذي وهني تتقصه هذه الفضائل والذي أخذ يردد إن الله اختاره لحكم العباد بقدره، ولا مرد من أمره، وعلى الرعية القبول

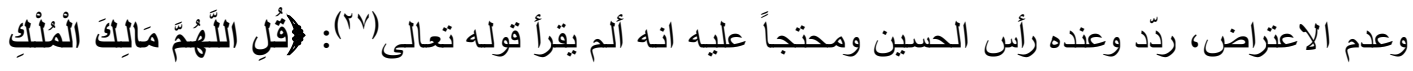

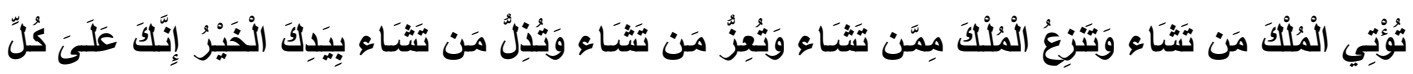

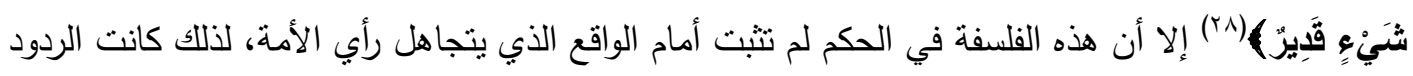
المعارضة قوية حتى من بني أمية أنفسهم، فقد رفض خليفة يزيد بن معاوية وابنه (معاوية) والملقب بـ(الراجع

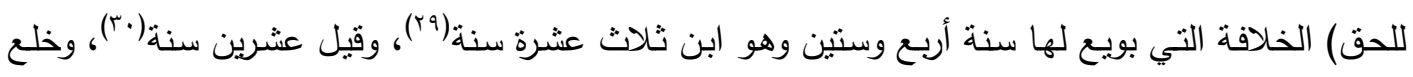
نفسه منها('r)، بعد أن صعد المنبر وألقى خطبة اختلف في بعض فحواها، إلا أنها نتبر إلى عدم قناعته 
بالخلافة، وإلى عدم رضاه عن سياسة بني أمية، وانتزاعهم الحكم من هم أحق منهم، ورفض أن يوصي (rr)، وانقطعت بعد ذلك أخباره، حيث ذكر انه دخل منزله ولم يخرج الى الناس، وتغيب الى ان مات، فقال بعض هض هُ

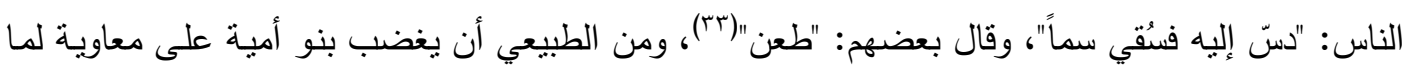
أقدم عليه، وحملوا معلمه (عمر المقصوص) انه وراء ذلك، فكان مصبيره أن دفنوه حياً حتى مات لعَّ).

أخذ الأمويون بعد ذلك بالبحث عن فلسفة جديدة مقنعة للناس يؤكد فيها أحقيتهم في الحكم، وأهمية الخلافة ودورها للناس، وإنْ كانت بعض الحجج التي احتجوا بها بعيدة عن الواقع وخروجاً عن الإسـلام، ولكي

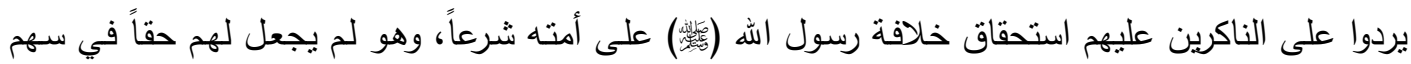
ذي القربى مع كونهم بني أبيه عبد مناف بن قصي، لما كان من عداوتهم له في دين الله تعالى وتكذيبهم لما

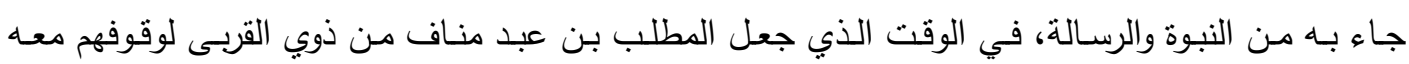
ومناصرتهم له، ودخلوا معه الشعب مؤمنهم وكافرهم، فالمؤمن ديناً والكافر حمية، فالقرابة وحدها ليست بشيء

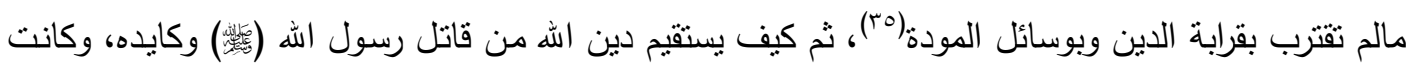

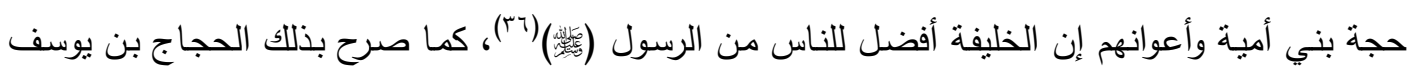
التقي يوماً وهو على المنبر بقوله وعلى رؤوس الأشهاد: "أرسولك لك أفضل أم خليفتك" ويقصد بالخليفة عبد

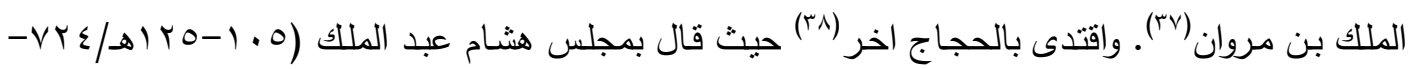

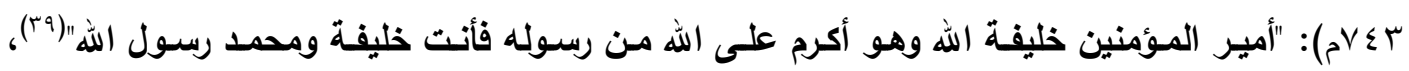

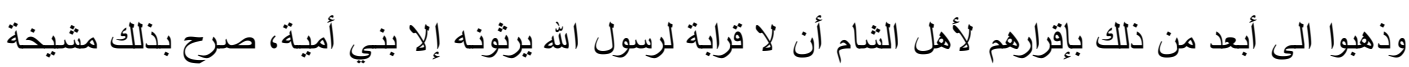

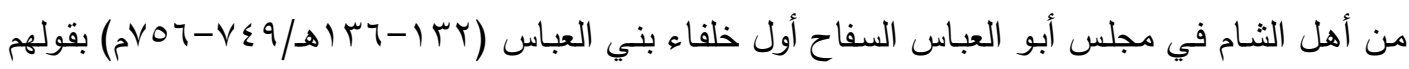

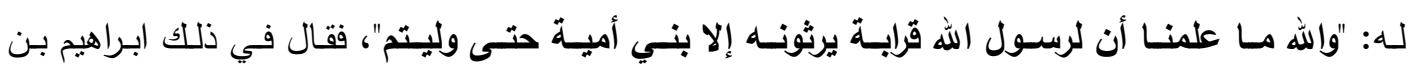

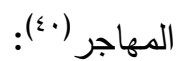

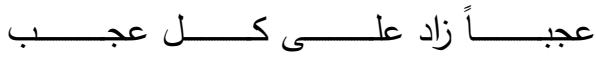

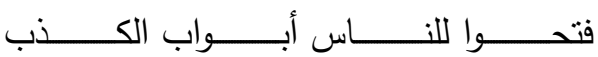

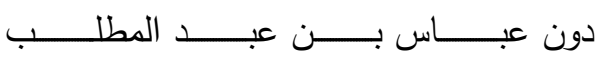

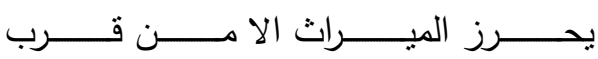
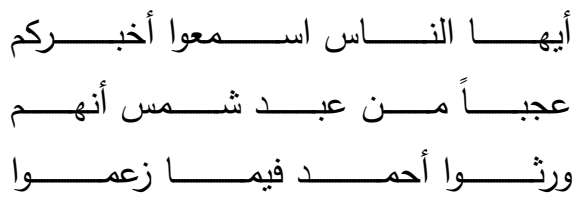

نعلمد

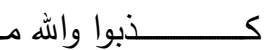


والجدير بالذكر ان البعض من المؤرخين فندوا مزاعم بني أمية في أحقيتهم في الخلافة، فالطبري يشير

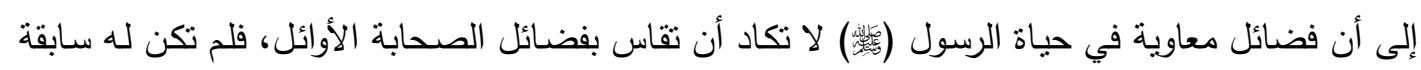

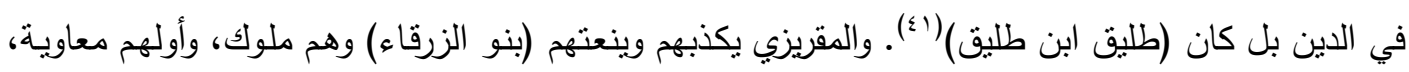

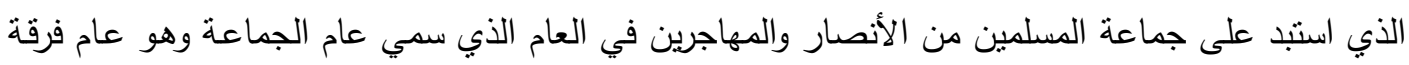

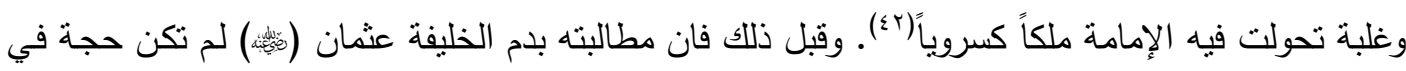

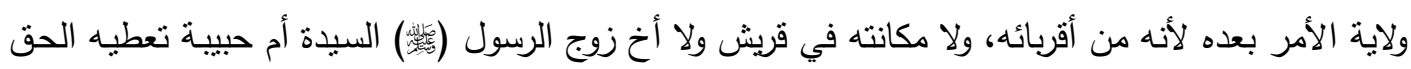

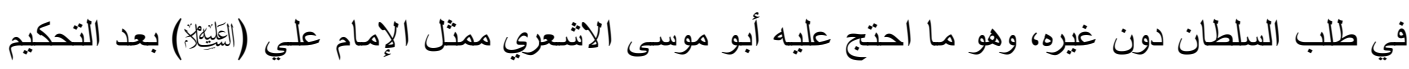

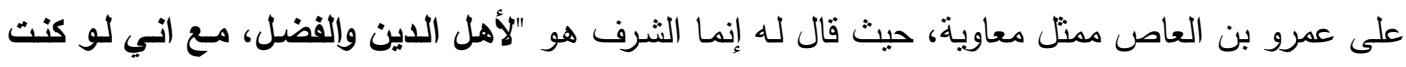

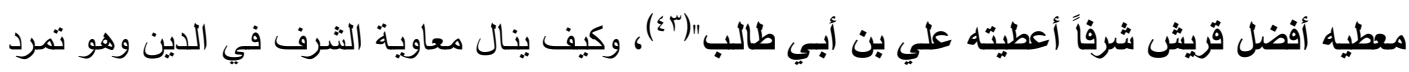

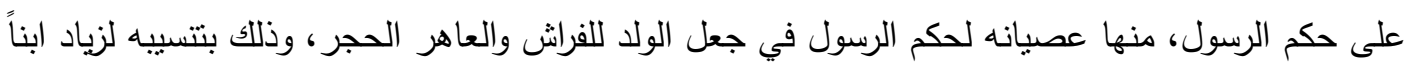

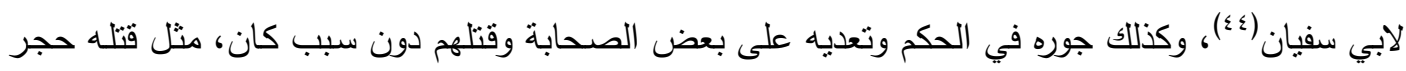

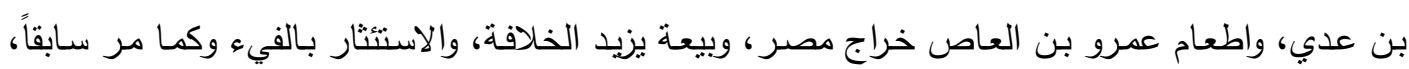

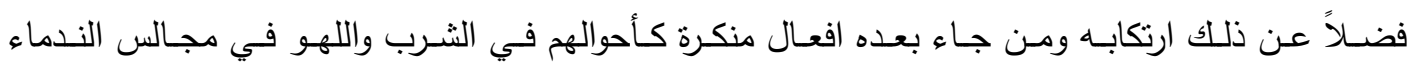

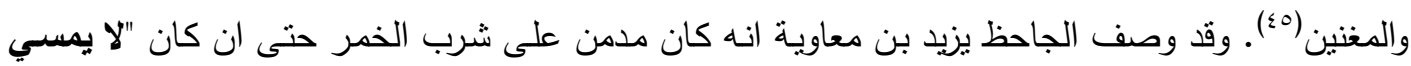

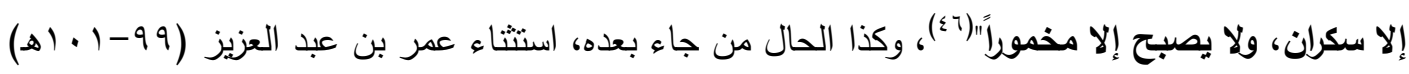

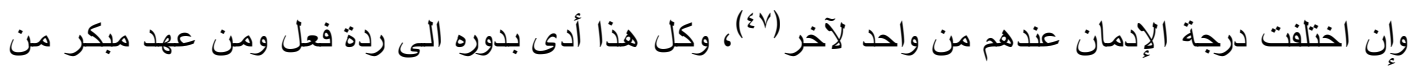

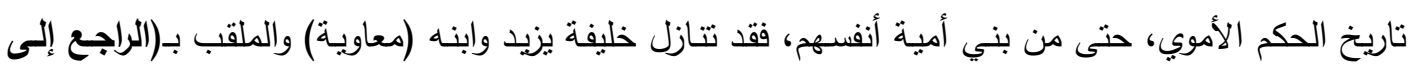

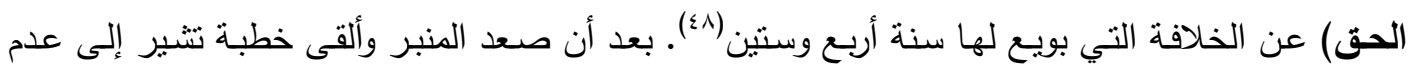
قناعته بالخلافة، وإلى عدم رضاه من سياسة جده وأبيه( (9).

وعلى أية حال، أدى نتازل معاوية الثاني عن الخلافة الى فراغ في سدة الحكم، وبالتالي زاد من تفاقم

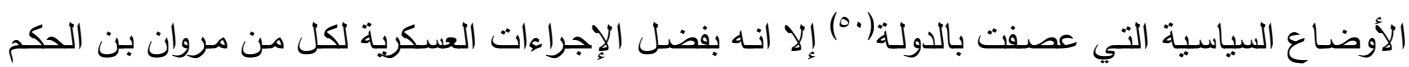

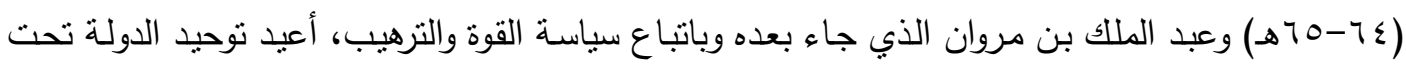

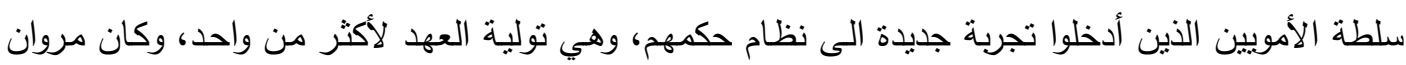

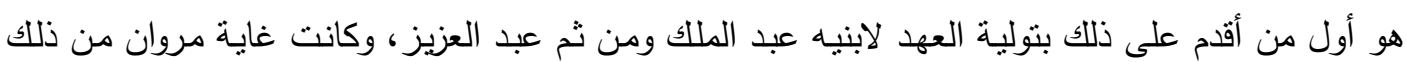


الحيلولة دون ابقاء منصب الخلافة شاغراً إن حدث لأحد المرشحين ما يخشى خطره، خاصة وإنّ بني أمية

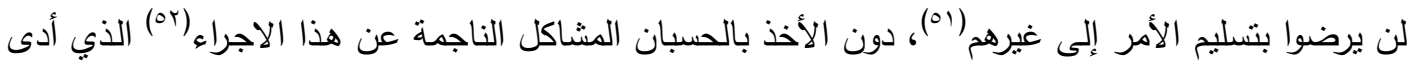

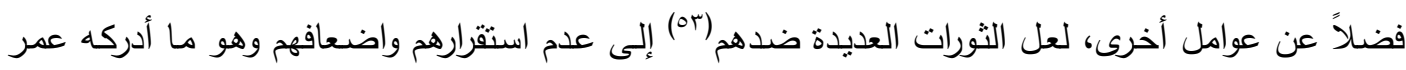

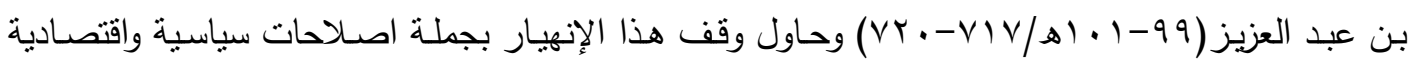

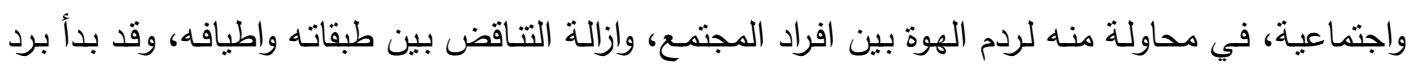

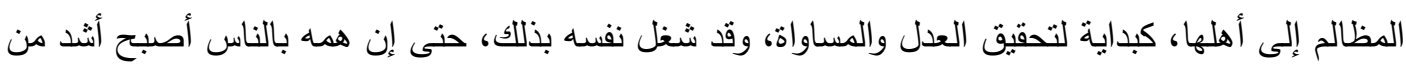

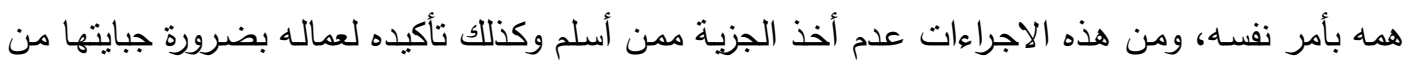

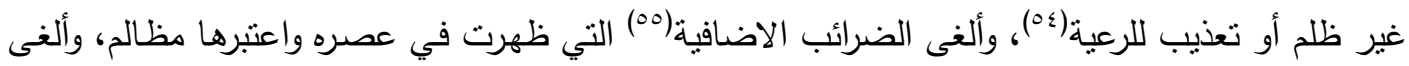

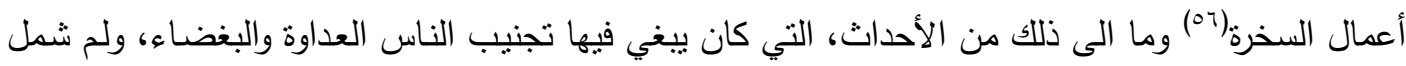

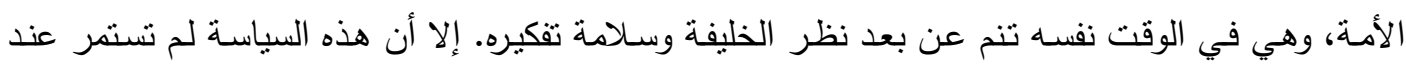

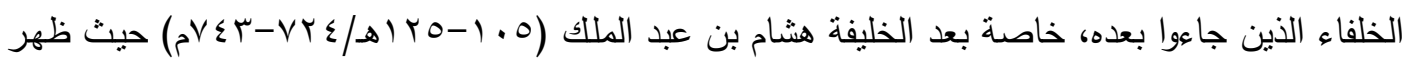

خلفاء ضعفاء انجرفوا مع تيارات قبلية وانشغلوا في اخماد اضطرابات مستمرة داخل بلاد الثام وخارجها.

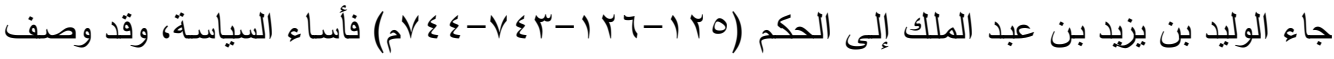

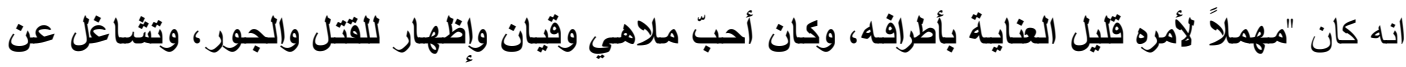

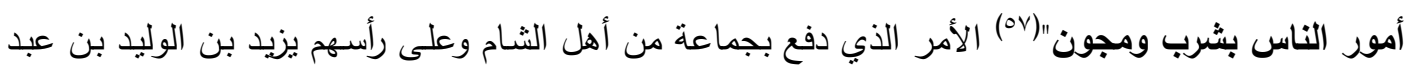

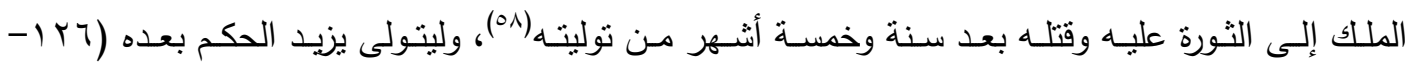

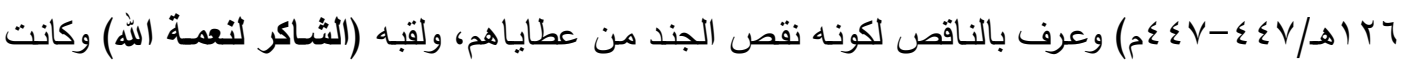

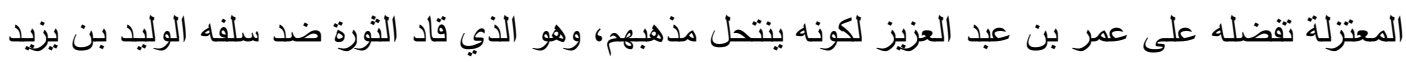

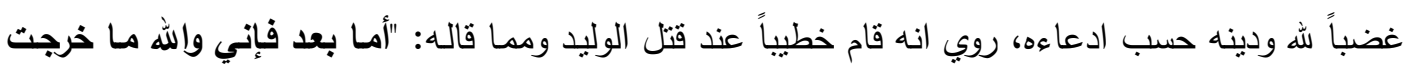

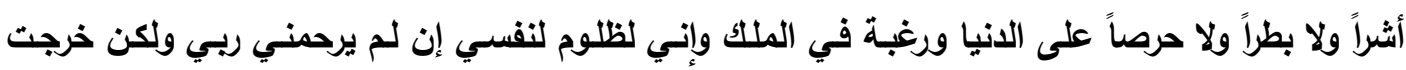

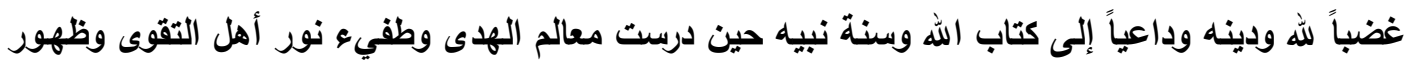

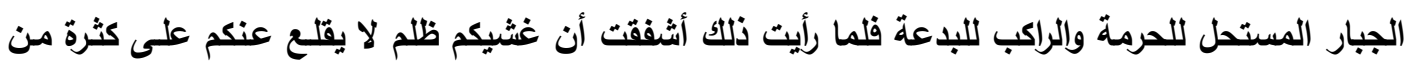

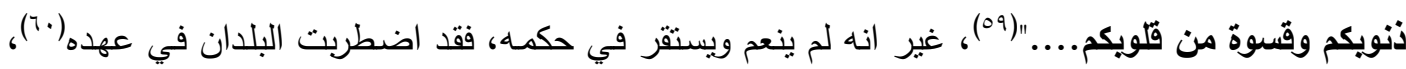

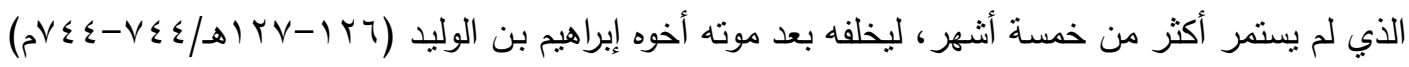




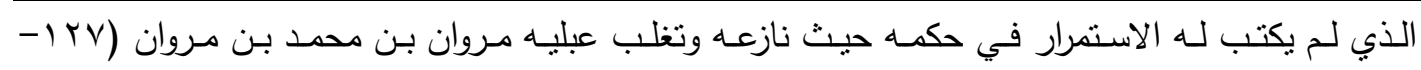

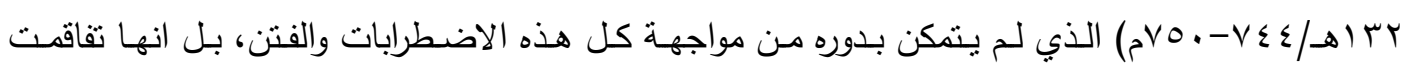

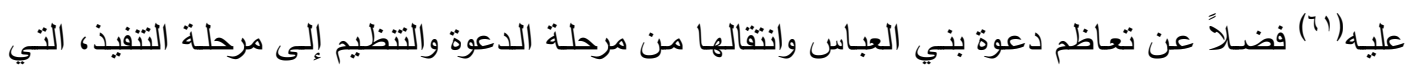

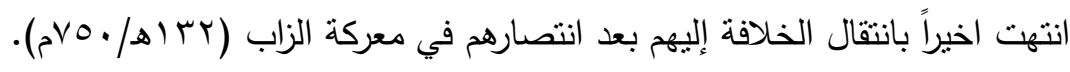


المصادر والمراجع

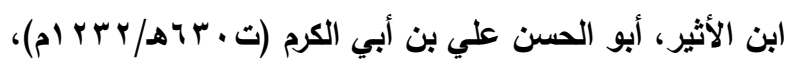

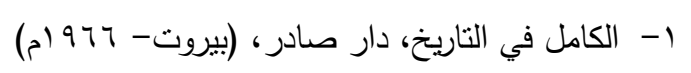

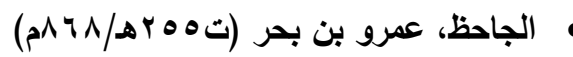

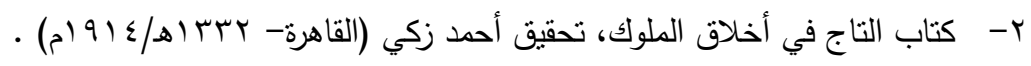

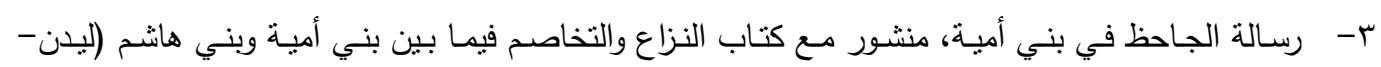

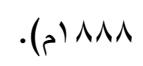

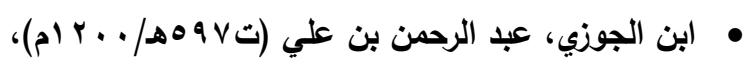

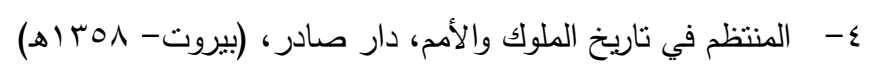

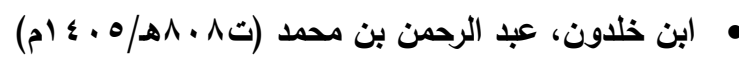

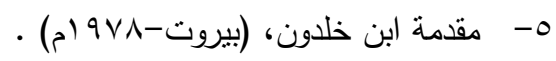

• الديار بكري، حسين بن محمد بن الحسن (من علماء القرن العاشر الهجري)،

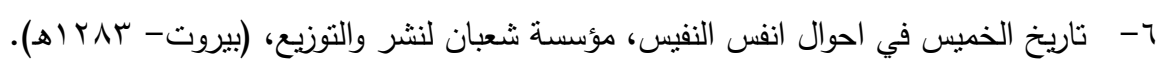

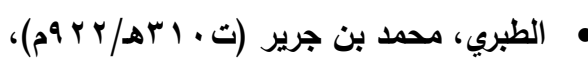

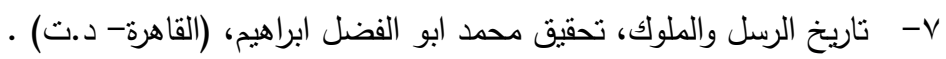

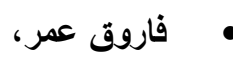

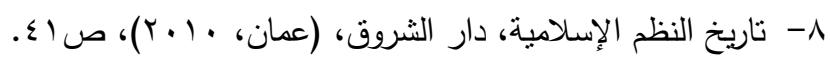

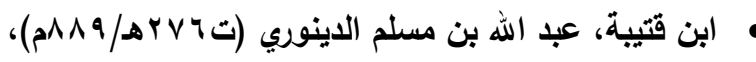

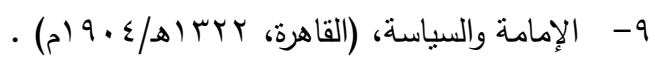

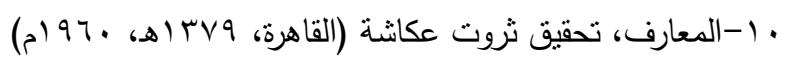

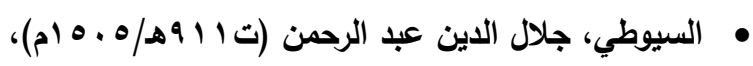

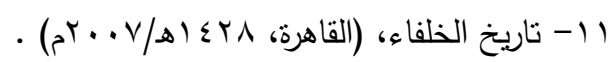

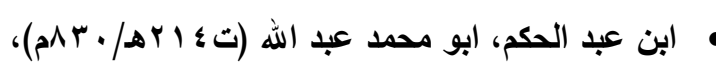

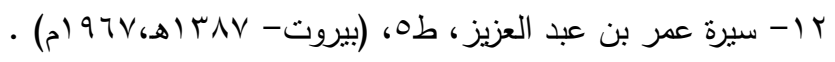




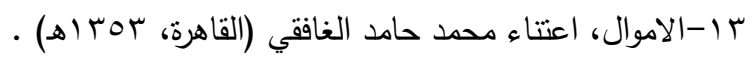

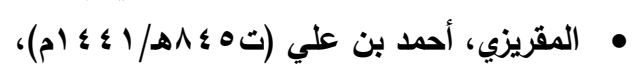

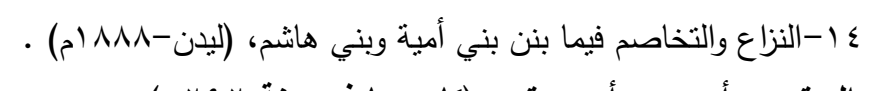

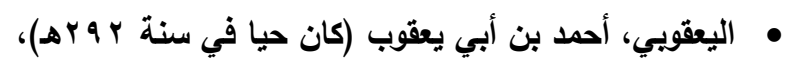

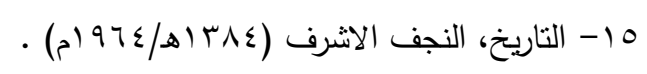

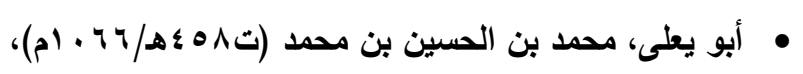

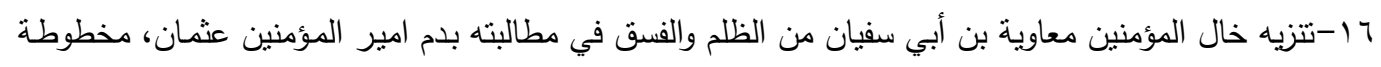

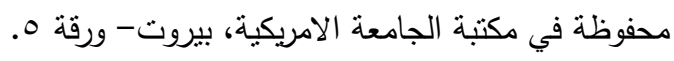

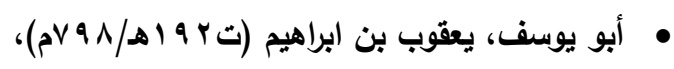

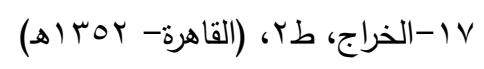




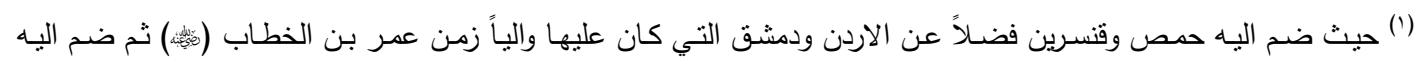

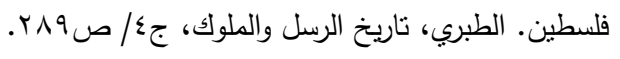

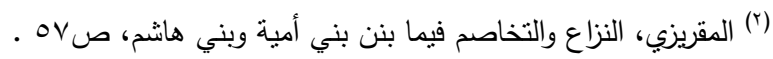

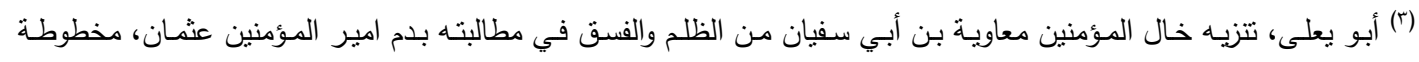

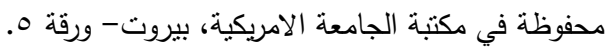

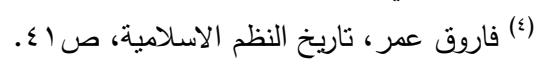

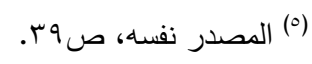

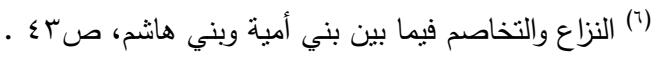

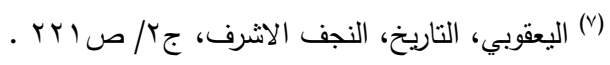

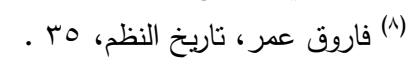

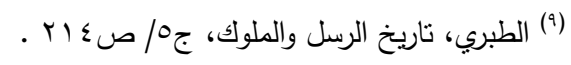

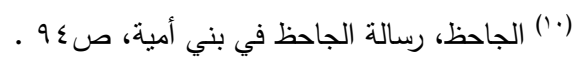

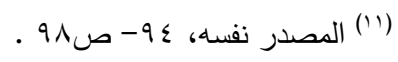

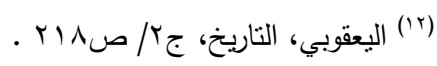

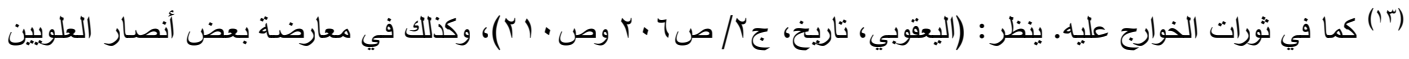

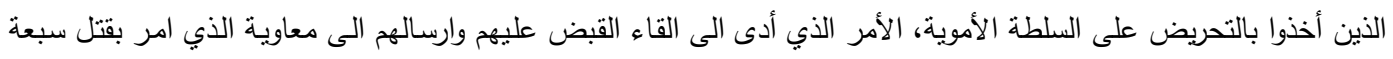

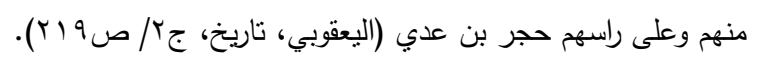

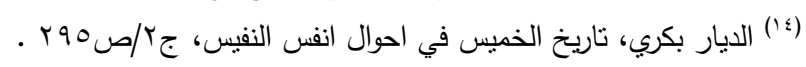

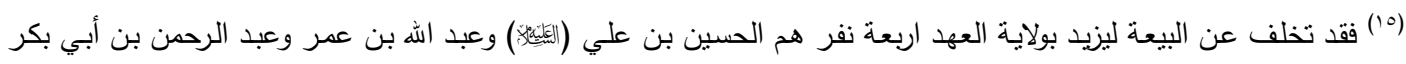

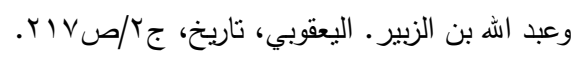

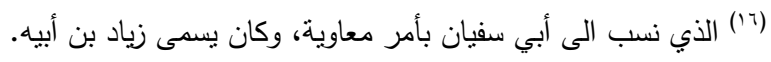

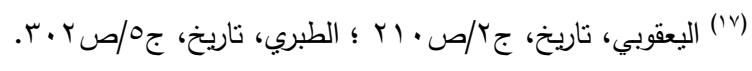

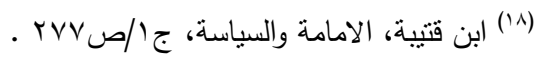

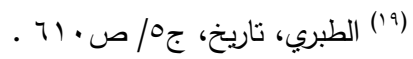

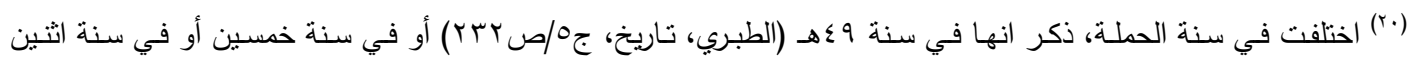

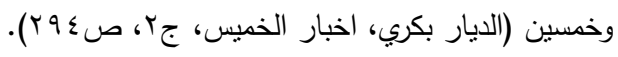

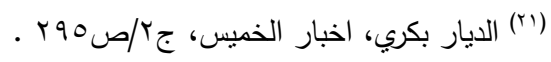

ro. 


$$
\begin{aligned}
& \text { (اليعقوبي، تاريخ، جrr) }
\end{aligned}
$$

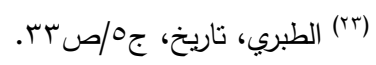

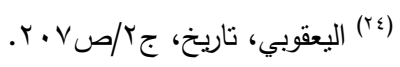

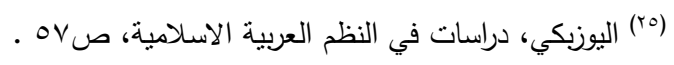

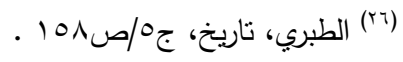

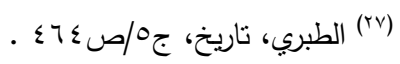

$$
\begin{aligned}
& \text { (r^) }
\end{aligned}
$$

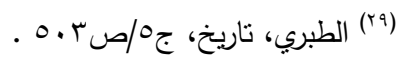

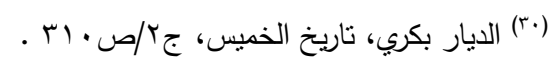

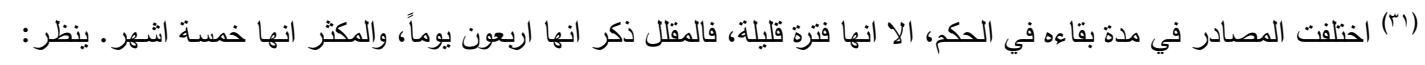

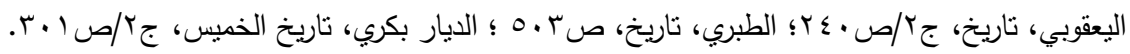

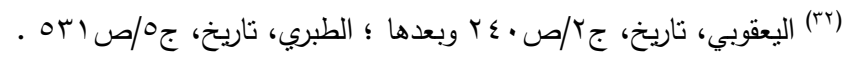

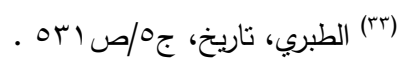

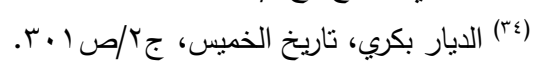

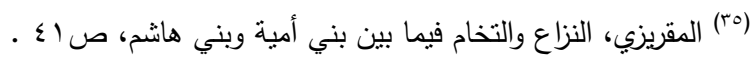

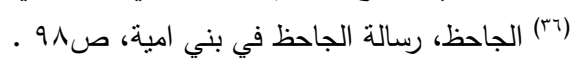

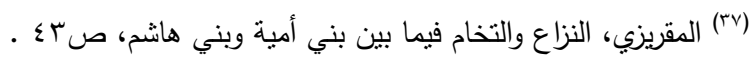

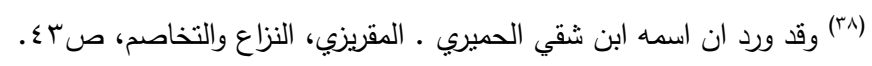

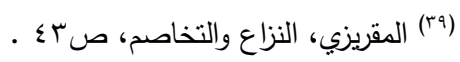

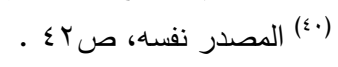

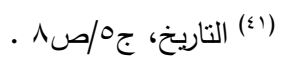

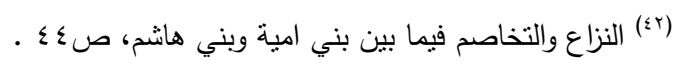

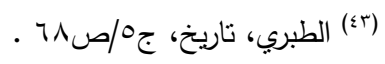

(ءء) والمجمع عليه ان ام زياد سمية لم تكن زوجة شرعية لابي سفيان. الجاحظ، رسالة الجاحظ في بني امية، صـ 9.

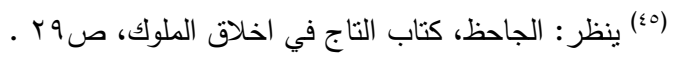

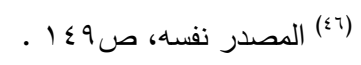

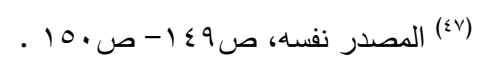




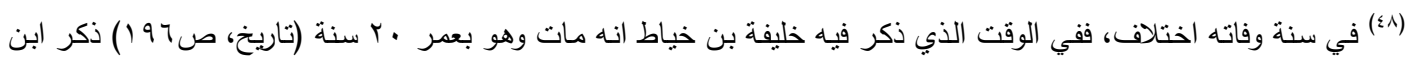

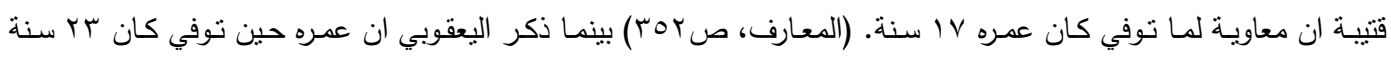

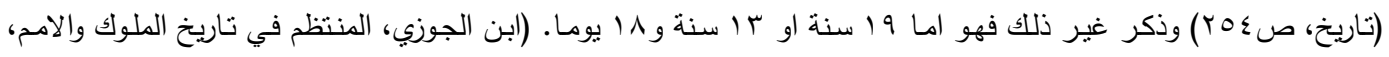

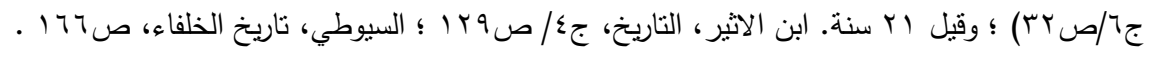

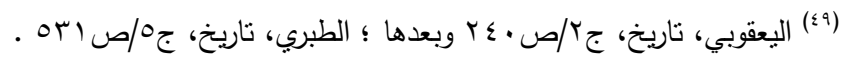

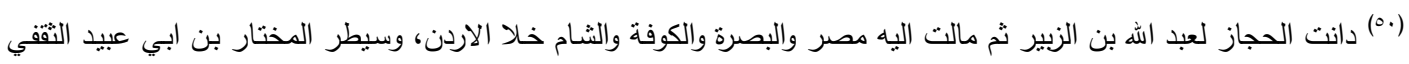

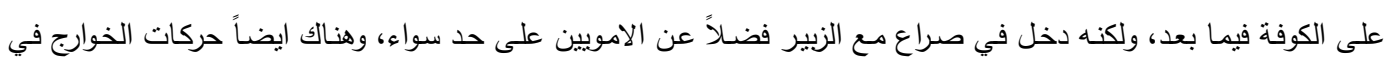

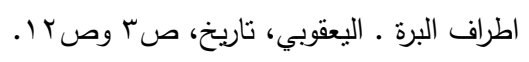

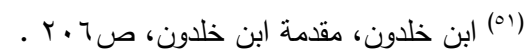

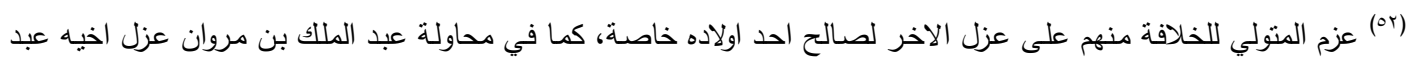

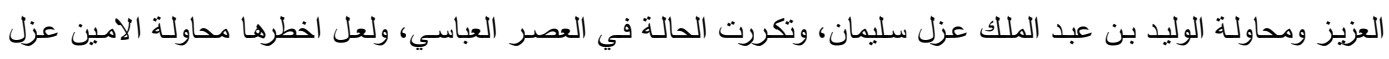

$$
\text { المأمون، وما نتج عن ذلك من اضطرابات وحروب. }
$$

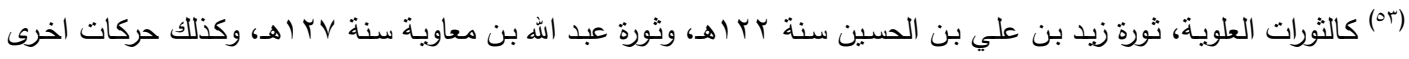

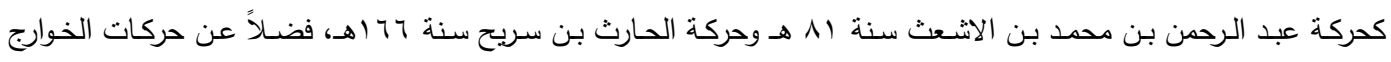

$$
\text { المستمرة. }
$$

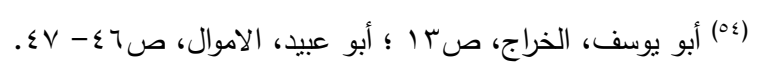

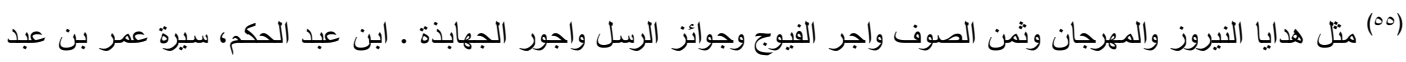

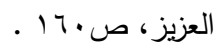

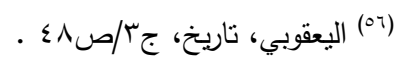

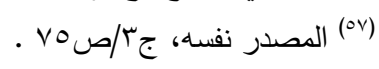

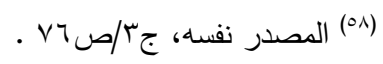

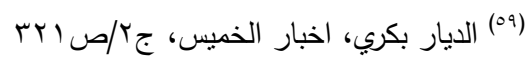

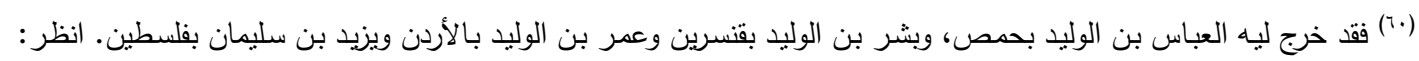

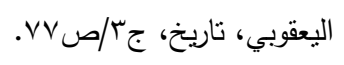

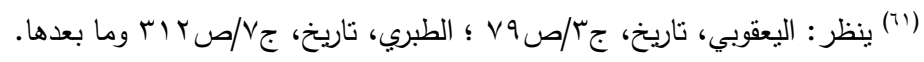

